\title{
Clinical features and prognostic factors of cerebral venous sinus thrombosis in a prospective series of 59 patients
} S F T M de Bruijn, R J de Haan, J Stam, for the Cerebral Venous Sinus Thrombosis Study
Group

\begin{abstract}
The prognosis of cerebral venous sinus thrombosis (CVST) is variable, and outcome may range from complete recovery to death. Prognostic factors to predict outcome in the acute phase of CVST have not been analysed in a prospective study. Prognostic factors in patients enrolled in a clinical treatment trial were prospectively investigated. Poor outcome after 12 weeks, defined as death or dependency (Oxford handicap score $\geqslant 3$ ), was used as the principle outcome measure. Univariate relations between possible prognostic factors and outcome at 12 weeks were analyzed with $\chi^{2}$ tests. Treatment and all factors associated with prognosis $(p \leqslant 0.25)$ were forced into a logistic regression model with a forward selection procedure.

Fifty nine patients (50 women, nine men) were studied, with a mean age of 37 years (range 18 to 80 years). After 12 weeks 10 patients $(17 \%)$ had a poor outcome. The univariate identified factors related to poor outcome were papilloedema, altered consciousness, coma, age older than 33 years, diagnostic delay $\leqslant 10$ days, intracerebral haemorrhage, and involvement of the straight sinus. Isolated intracranial hypertension and a delta sign on CT were associated with good outcome. In the multivariate analysis coma and cerebral haemorrhage were significantly associated with a poor outcome, with odds ratios of 8.2 (95\% confidence interval (95\% CI) 1.3-50.1) and 20.7 (95\% CI 1.6-264.3) respectively. Involvement of the straight sinus was also weakly, but not significantly, associated with poor outcome.

In conclusion, coma and intracerebral haemorrhage are independent predictors for poor outcome of CVST.

(F Neurol Neurosurg Psychiatry 2001;70:105-108)
\end{abstract}

Correspondence to: Dr SFTM de Bruijn, Department Of Neurology, Leyenburg Hospital, Leyweg 275, $2545 \mathrm{CH}$ The Hague,

The Netherlands

sdebruijn@

neurologie-denhaag.n

Received 23 February 2000 and in revised form

7 August 2000

Accepted 15 August 2000 venous sinus thrombosis may vary from complete recovery to permanent neurological deficits, as a natural course of the disease. ${ }^{12}$ Treatment with anticoagulant drugs leads to a moderate benefit for patients with CVST compared with placebo treatment, ${ }^{34}$ but the mortality after treatment with anticoagulant drugs is still $5 \%$ to $10 \% .{ }^{4}$ Thrombolytic treatment, reported as a safe and effective treatment for CVST in small non-randomised case series, may be beneficial for selected patients but should still be regarded as experimental..$^{5-8}$

In the acute phase it is important to identify those patients who have a poor prognosis, because this may influence therapeutic strategy, and enables the treating physician to give reliable information to the patient and relatives. Prognostic factors for CVST have been suggested, including coma, the presence of cerebral haematoma and infarctions, seizures, age, and neurological deficits, based on data from case reports or retrospective series. ${ }^{19-12}$

We therefore investigated clinical and other characteristics in a prospective series of 59 patients with CVST, to identify prognostic factors that predict a poor outcome.

\section{Patients and methods}

We prospectively investigated all patients who were randomised in the Dutch-European Cerebral Sinus Thrombosis trial. In this trial treatment with low molecular weight heparin for 3 weeks was compared with placebo in a double blind design. ${ }^{4}$ Sinus thrombosis had to be confirmed by conventional angiography or MRI in combination with magnetic resonance angiography (MRI/MRA). Reasons for exclusion were age younger than 18 years; cavernous sinus thrombosis; pregnancy; indications or contraindications for heparin; conditions with a poor prognosis unrelated to CVST; impaired vision by optic nerve papilloedema that required lumbar punctures or CSF shunting, and a recent lumbar puncture or surgical procedure.

We investigated all relevant data from the patient record forms, and also the results of laboratory data and imaging techniques (table). Outcome was assessed after 12 weeks with the Oxford handicap score (modified Rankin scale). ${ }^{13}$ Poor outcome after 12 weeks, 
Clinical and other possible prognostic factors related to outcome 12 weeks after CVST in 59 patients

\begin{tabular}{|c|c|c|c|c|c|}
\hline Neurological signs and symptoms & $n$ & $\%$ & $\begin{array}{l}\text { Poor } \\
\text { outcome } \\
(n=10)\end{array}$ & $\begin{array}{l}\text { Good } \\
\text { outcome } \\
(n=49)\end{array}$ & $\begin{array}{l}p \text { Value }\left(\chi^{2} \text { or }\right. \\
\text { Fisher's exact) }\end{array}$ \\
\hline Recent headache & $56 / 59$ & 95 & 9 & 47 & 0.43 \\
\hline Focal deficitst & $27 / 59$ & 46 & 5 & 22 & 1.0 \\
\hline Paresis ${ }^{\star}$ & $20 / 50$ & 40 & 3 & 17 & 0.38 \\
\hline Dysphasia* & $11 / 50$ & 22 & 2 & 9 & 0.30 \\
\hline Visuospatial disorder $\star$ & $4 / 50$ & 9 & 1 & 3 & 0.35 \\
\hline Homonymous hemianopia ${ }^{\star}$ & $3 / 50$ & 6 & 0 & 3 & 1.0 \\
\hline Seizures & $28 / 59$ & 47 & 5 & 23 & 1.0 \\
\hline Generalised seizures & $22 / 59$ & 37 & 4 & 18 & 1.0 \\
\hline Focal seizures only & $6 / 59$ & 10 & 1 & 5 & 1.0 \\
\hline Papilloedema ${ }^{\star}$ & $23 / 56$ & 41 & 5 & 18 & 0.25 \\
\hline Impaired consciousness $(\mathrm{GCS}<14)$ & $23 / 59$ & 39 & 8 & 15 & $<0.01$ \\
\hline Coma $(\mathrm{GCS} \leqslant 8)$ & $9 / 59$ & 15 & 5 & 4 & $<0.01$ \\
\hline Isolated intracranial hypertension & $12 / 59$ & 20 & 0 & 12 & 0.10 \\
\hline Transient neurological symptoms (TIA-like episodes) & $8 / 59$ & 14 & 1 & 7 & 1.0 \\
\hline Brain stem/cerebellar signs ${ }^{\star}$ & $6 / 50$ & 12 & 0 & 6 & 1.0 \\
\hline Visual impairment ${ }^{\star}$ & $5 / 50$ & 10 & 1 & 4 & 0.42 \\
\hline \multicolumn{6}{|l|}{ Other possible prognostic factors: } \\
\hline Age $>33$ y & $29 / 59$ & 49 & 7 & 22 & 0.18 \\
\hline Diagnostic delay $\leqslant 10$ days & $35 / 59$ & 59 & 8 & 27 & 0.18 \\
\hline Any coagulation disorder ${ }^{\star}$ & $19 / 52$ & 37 & 1 & 18 & 0.64 \\
\hline Puerperium & $7 / 59$ & 12 & 0 & 7 & 0.59 \\
\hline Cerebral haemorrhage (CT/MRI) & $29 / 59$ & 49 & 9 & 20 & $<0.01$ \\
\hline Erythrocytes in $\mathrm{CSF}^{\star}$ & $12 / 24$ & 50 & 1 & 11 & 1.0 \\
\hline Delta sign on CT & $18 / 57$ & 32 & 1 & 17 & 0.15 \\
\hline Involvement superior sagittal sinus & $50 / 59$ & 85 & 10 & 40 & 0.33 \\
\hline Involvement straight sinus & $17 / 59$ & 29 & 5 & 12 & 0.13 \\
\hline Treatment with nadroparin (high dose) & $30 / 59$ & 51 & 4 & 26 & 0.51 \\
\hline
\end{tabular}

GCS=Glasgow coma score.

${ }^{\star}$ Could not be assessed in the remaining patients.

†Signs that could not be assessed were scored negative.

defined as death or an Oxford handicap score of 3 or greater, was used as outcome measure for assessment of prognostic factors.

STATISTICAL ANALYSIS

$\chi^{2}$ Tests (or Fisher's exact test when appropriate) were performed to analyse the univariate relations between possible prognostic factors (table) and outcome at 12 weeks. As it is likely that different prognostic factors are mutually related, the independent effects of prognostic factors were additionally analysed with multivariate logistic regression, including the treatment factor. Subsequently, besides the treatment factor, all variables with $p \leqslant 0.25$ identified in the univariate analysis were presented to a logistic regression model to assess their independent prognostic value. In all univariate analyses missing values were excluded. In the multivariable regression model the few missing data were scored as absent. Significant prognostic factors were selected with a forward selection strategy using the likelihood ratio statistic, with $\mathrm{p}=0.05$ the criterion level for selection. Effect sizes were expressed as odds ratios (ORs, calculated as the antilogarithm of the regression coefficients in the logistic regression model) with $95 \%$ confidence intervals (95\% CIs). The OR can be interpreted as an estimation of the relative risk of poor outcome. Calibration of the logistic regression model was assessed with the Hosmer-Lemeshow goodness of fit test. ${ }^{14}$ This test compares observed and expected frequencies of the outcomes in groups based on the values of the estimated probabilities, using the logistic model. In this test, a high $\mathrm{p}$ value indicates that the model is performing well-that is, there is little discrepancy between observed and expected outcome.

\section{Results}

Between July 1992 and November 199660 patients were recruited in 14 hospitals in The Netherlands and the United Kingdom. No patients were lost to follow up. One patient was ineligible due to a wrong diagnosis (arterial cerebral infarction). Thus 59 patients (50 women, nine men) were studied. Mean age was 37 years, with a range from 18 to 80 years (median 33 years).

After 12 weeks six patients had died, and four patients had an Oxford handicap score of 3 or more, which results in 10 of the 59 patients $(17 \%)$ with a poor outcome. All patients at entry without intracerebral haemorrhage, and who were not in coma (GCS $\leqslant 8$ ) had a good outcome after 12 weeks.

The neurological symptoms and signs at admission are summarised in the table. Headache is the most frequent symptom, present in $95 \%$ of the patients. Other often occurring symptoms were seizures $(28 / 59,47 \%)$, paresis $(23 / 54,43 \%)$, and papilloedema $(23 / 56,41 \%)$. Nine patients (15\%) presented in coma and 23 (39\%) had some degree of impaired consciousness. Twelve patients $(20 \%)$ presented with a clinical syndrome of isolated intracranial hypertension (headache with or without papilloedema or visual impairment, and no other symptoms and signs).

The mean delay between the onset of symptoms and the time of randomisation at admission was 10.6 days (range 1 to 30 days, median 8 days). Five patients (9\%) had an acute onset, with symptoms developing within 48 hours before the diagnosis. There were no patients with progression over more than a month. There were no infective cases. Seven of the 50 female patients $(14 \%)$ were in the puerperium and $35(70 \%)$ used oral contraceptives. 
Antiphospholipid antibodies were examined in 42 patients, and were positive in six (14\%). Factor $\mathrm{V}$ leiden mutation was present in seven of the 51 patients $(14 \%)$, protein C deficiency in two $(2 \%)$, and hyperhomocysteinemia in six of the 15 patients $(40 \%)$ in whom it was examined. No possible cause for CVST could be identified in 10 patients $(17 \%)$.

Twenty nine patients had signs of cerebral haemorrhage on their baseline CT or MRI $(49 \%)$. Magnetic resonance imaging or conventional angiography showed involvement of the superior sagittal sinus in 50 patients (88\%); in 14 of them the straight sinus was also involved. Overall the straight sinus was thrombosed in 17 cases $(29 \%)$.

PROGNOSTIC FACTORS

The univariate identified factors associated with a poor outcome $(\mathrm{p} \leqslant 0.25)$ were papilloedema, impaired consciousness, coma, age older than 33 years, diagnostic delay $\leqslant 10$ days, intracerebral haemorrhage, and involvement of the straight sinus (table). Isolated intracranial hypertension and a delta sign on CT were associated with a good outcome $(p \leqslant 0.25)$. Logistic regression showed that coma and cerebral haemorrhage were independent, significant predictors of poor outcome, with ORs of 8.2 (95\% CI 1.3-50.1) and 20.7 (95\% CI 1.6264.3) respectively (Hosmer-Lemeshow test, $\mathrm{p}=0.54)$. Involvement of the straight sinus also predicted poor outcome but this association was not significant $(p=0.07)$. As coma and impaired consciousness overlapped, and because of the small sample size, we only analysed coma in the multivariate regression analysis.

\section{Discussion}

Overall outcome was fairly good, with independent survival of $83 \%$ of the patients (Oxford handicap score $\leqslant 2$ ). Coma at the time of diagnosis (Glasgow coma scale $\leqslant 8$ ) and haemorrhage on the initial CT were independent predictors of poor outcome for patients with sinus thrombosis. Involvement of the straight sinus tended to be associated with a poor outcome.

There are limitations of the study. The number of potential prognostic factors which can be analysed in multivariate analysis is limited to about six in a series of 59 patients. ${ }^{15}$ Additional testing for the goodness of fit of our logistic model indicated that the model fits the data well. Ideally, however, the predictive value of the prognostic factors should be tested in a new independent prospective series of patients. Although the trial covered the full range of clinical presentations of CVST, the applicability of our findings is still limited to those patients who met the inclusion and exclusion criteria of the trial. We chose independent survival as the main outcome measure. This outcome is clinically very important, but more subtle cognitive deficits are missed. Recent long term follow up study of 47 surviving patients with CVST in the trial showed that $29 \%$ of the patients who were independent at least 1 year after CVST still had cognitive impairments, and $40 \%$ could not resume their previous level of economic activity. ${ }^{16}$

Other studies about prognosis of sinus thrombosis are scarce. In a retrospective univariate analysis of 78 patients with CVST coma, bilateral cerebral haematoma or haemorrhagic infarction, and haemorrhagic CSF were identified as predictors of a poor outcome. Bilateral pyramidal tract signs and generalised seizures were also associated with a poor outcome. ${ }^{9}$ In a retrospective series of 62 patients with CVST from our own institute, coma, paresis, and intracerebral haemorrhages or haemorrhagic infarctions were associated with a poor prognosis. ${ }^{12}$ In a univariate analysis of 18 consecutive patients with CVST no significant predictors were found, but there was a tendency towards a better outcome at 1 month for younger patients and for patients with isolated intracranial hypertension. ${ }^{17}$ Other previously reported predictors for poor outcome, which are not confirmed in our study are age $^{10}$ and the presence of focal neurological deficits. ${ }^{11}$ Septic CVST, also regarded as a possible poor prognostic factor, ${ }^{18}$ was not present in our study.

Thrombosis of the deep venous system is known to cause bilateral thalamic lesions, which may cause cognitive dysfunctioning (especially memory disturbances), coma, or death. Prognosis is considered poor, but good recovery has been reported in some cases. ${ }^{19-21}$ Our analysis indicates that involvement of the straight sinus and the deep venous system may be an additional predictor of poor outcome. Isolated thrombosis of the straight sinus is rare; usually there is also involvement of the deep venous system (Galenic system) or the superior sagittal sinus.

Univariate analysis showed that heparin treatment was not related to outcome. Metaanalysis of the results of two randomised studies, ${ }^{34}$ including the trial from which the data of this study are analyzed, showed a modest beneficial effect ( $12 \%$ risk reduction of death) of any heparin treatment that was almost statistically significant. Heparin is considered the treatment of first choice in patients with CVST by most experts, because it is safe and probably beneficial. ${ }^{8}$ Nevertheless, it is clear that a substantial number of patients with CVST may recover completely without any treatment. ${ }^{82}$ This study shows that the condition of the patient at the time of the diagnosis is far more important for the final outcome than whether the patient was treated with heparin. Endovascular thrombolytic therapy is reported as a safe and effective treatment for CVST in some uncontrolled case series, ${ }^{5-7}$ unless pretreatment cerebral haemorrhages are present. ${ }^{8}$ Because it is invasive and potentially dangerous it should be considered only in patients with a poor prognosis.

We conclude that the overall prognosis of CVST is fairly good, at least for independent survival. Coma and intracerebral haemorrhage are independent predictors for poor outcome, and involvement of the straight sinus is a possible additional unfavourable factor. Future treatment studies, especially with thrombolysis, 
should be directed to the subgroup of patients with sinus thrombosis with a poor prognosis.

Cerebral Venous Sinus Thrombosis Study Group: SFTM de Bruijn (Leyenburg Hospital, The Hague), J Stam (Academic Medical Centre, Amsterdam), LJ Kappelle, J Van Gijn Medical Centre, Amsterdam), LJ Kappelle, J Van Gijn (Academic Hospital, Utrecht), DWJ Dippel, PJ Koudstaal, (Dijkzigt Academic Hospital, Rotterdam), JJ van Hilten, RAC Roos (Academic Hospital, Leiden), JJ van der Sande, HL Ham-
burger (Slotervaart Ziekenhuis, Amsterdam), JLA Eekhof burger (Slotervaart Ziekenhuis, Amsterdam), JLA Eekhof
(Diaconessenhuis, Leiden), CL Franke (de Wever Ziekenhuis, Heerlen), J Lodder (Academic Hospital, Maastricht), CC Tijssen (St Elisabeth ziekenhuis, Tilburg), FW Bertelsman, JC Koetsier (Academic Hospital, Free University, Amsterdam), P Sandercock (Western General Hospital, Edinburgh), P Humphrey (The Walton Centre, Liverpool), GN Mallo (Flevoziekenhuis, Almere), P Verlooy, HK van Walbeek (Onze Lieve Vrouwen Gasthuis, Amsterdam), JW Snoek (Martini ziekenhuis, Groningen). Study medication and partial financial support were provided by Sanofi-Winthrop (Dutch division).

1 Bousser M, Chiras J, Bories J, et al. Cerebral venous thrombosis: a review of 38 cases. Stroke 1985;16:199-213.

2 Einhäupl KM, Villringer A, Haberl RL, et al. Clinical spectrum of sinus venous thrombosis. In: Einhäupl KM,
Kempski O, Baethmann A, eds. Cerebral sinus thrombosis Experimental and clinical aspects. New York: Plenum Press, 1990:149-56.

3 Einhäupl KM, Villringer A, Meister W, et al. Heparin treatment in sinus venous thrombosis. Lancet 1991;338:597600.

4 Bruijn de SFTM, Stam J, for the Cerebral Venous Sinus Thrombosis Study Group. Randomised placebo-controlled trial of anticoagulant treatment with low-molecular-weigh heparin for cerebral sinus thrombosis. Stroke 1999;30:484-8

5 Horowitz M, Purdy P, Unwin H, et al. Treatment of dural sinus thrombosis using selective catheterization and urokinase. Ann Neurol 1995;38:58-67.

6 Di Rocco C, Iannelli A, Leone G, et al. Heparin-urokinase treatment in aseptic dural sinus thrombosis. Arch Neurol 1981;38:431-5.
7 Kim SY, Suh JH. Direct endovascular thrombolytic therapy for dural sinus thrombosis: infusion of alteplase. $\mathrm{Am} \mathrm{F} \mathrm{Neu-}$ roradiol 1997;18:639-45.

8 Frey JL, Muro GJ, McDougall CG, et al. Cerebral venous thrombosis: combined intrathrombus rtPA and intravenous heparin. Stroke 1999;30:489-94.

9 Barinagarrementeria F, Cantu C, Arredondo H. Aseptic cerebral venous thrombosis: proposed prognostic scale. $\mathcal{F}$ Stroke Cerebrovasc Dis 1992;2:34-9.

10 Kalbag RM, Woolf AL. Cerebral venous thrombosis. London: Oxford University Press, 1967.

1 Preter M, Tzourio C, Ameri A, et al. Long-term prognosis in cerebral venous thrombosis. Follow-up of 77 patients. Stroke 1996;27:243-6.

12 Bienfait HP, Stam J, Lensing AWA, et al. Trombose van de cerebrale venen en sinussen bij 62 patienten. Ned Tijdschr Geneeskd 1995;139:1286-91.

13 Rankin J. Cerebral vascular accidents in patients over the age of 60. II. Prognosis. Scott Med f 1957;2:200-15.

14 Hosmer DW, Lemeshow S. Applied logistic regression. New York: John Wiley, 1989:140-5.

15 Altmann DG. Practical statistics for medical research. first ed. London:Chapman and Hall, 1991.

16 Bruijn de SFTM, Budde M, Teunisse S, et al. Long-term outcome of cognition and functional health after cerebral venous sinus thrombosis. Neurology 2000;54:1687-9.

17 Rondepierre P, Hamon M, Leys D, et al. Thromboses veineuses cérebrales: étude de l'évolution. Rev Neurol (Paris) 1995;151:100-4.

18 Infections of the dural venous sinuses [editorial]. Lancet $1987 ; \mathrm{i}: 201-2$

19 Haley EC, Brashear R, Barth JT, et al. Deep cerebral venous thrombosis. Clinical, neuroradiological, and neuropsychological correlates. Arch Neurol 1989;46:337-40.

20 Bots GTAM. Thrombosis of the galenic system veins in the adult. Acta Neuropathol 1971;17:227-33.

21 Ur-Rahman N, Al-Tahan AR. Computed tomographic evidence of an extensive thrombosis and infarction of the deep venous system. Stroke 1993;24:744-6.

22 Bousser M, Russell RR. Cerebral venous thrombosis. London: WB Saunders, 1997. 